\title{
Los movimientos sociales de Bolivia como actores contrahegemónicos en el régimen internacional de control de drogas
}

\section{Daniel Salgar Antolínez*}

\section{RESUMEN}

El régimen internacional de control de drogas vigente prohíbe el cultivo de la coca en su estado natural y su uso tradicional. Sin embargo, impulsado por movimientos sociales en defensa del uso tradicional de la coca, el Estado de Bolivia en 2011 denunció la Convención Única de Estupefacientes -principal instrumento del régimen- y luego fue readmitido con una reserva sobre la masticación de la coca. ¿Por qué esa defensa de la coca por parte de los movimientos sociales, a través del Estado, puede entenderse como una práctica contra hegemónica en este régimen internacional desde la llegada de Evo Morales a la Presidencia? Este análisis cualitativo mostrará que el Estado no llegó a articular un bloque hegemónico internacional, pero tiene un comportamiento contra hegemónico al visibilizar prácticas y saberes históricamente excluidos.

Palabras clave: hoja de coca, régimen internacional de control de drogas, movimientos sociales, Bolivia, Evo Morales.

\section{Bolivia's social movements as counter-hegemonic actors in the international drug control regime}

\section{ABSTRACT}

The current international drug control regime prohibits the cultivation of coca in its natural state and its traditional use. However, promo-

\footnotetext{
Maestría en asuntos internacionales. Editor general del servicio en español de la Agencia de Noticias Anadolu (Turquía). [salgardaniel@gmail.com], [https://orcid.org/0000-0001-8099-2764].

Recibido: 10 de abril de 2019 / Modificado: 25 de junio de 2019 / Aceptado: 19 de julio de 2019

Para citar este artículo:

Salgar Antolínez, D. (2020). Los movimientos sociales de Bolivia como actores contrahegemónicos en el régimen internacional de control de drogas. OASIS, 31, pp. 215-233

DOI: https://doi.org/10.18601/16577558.n31.12
} 
ted by social movements, the State of Bolivia in 2011 denounced the Single Convention on Narcotic Drugs -main instrument of the regime- and then was readmitted with a reservation on coca chewing. Why this Bolivian social movement's defense of coca through the State can be understood as a counterhegemonic practice in this international regime since the arrival of Evo Morales to the presidency? This qualitative analysis shows that the state did not articulate an international hegemonic bloc, but it has a counterhegemonic behavior when visibilizing historically excluded practices and forms of knowledges.

Key words: Coca leaf, international drug control regime, social movements, Bolivia, Evo Morales.

\section{INTRODUCCIÓN}

La primera conferencia internacional para enfrentar el "problema mundial de las drogas" fue la Comisión Internacional del Opio de Shangai, en 1909, la cual emitió una resolución con nueve recomendaciones, la mayoría sobre el problema del opio en China y otras dirigidas a eliminar paulatinamente el consumo de opio en países miembros (Unodc, 2008; Sánchez, 2014). Hasta 1912 se firmó el primer tratado multilateral vinculante, la Convención Internacional del Opio de La Haya, que materializó las recomendaciones emitidas tres años antes. En adelante se firmaron varias convenciones, acuerdos y protocolos, y se crearon organismos de control que componen el régimen internacional de control de drogas.

La Convención Única de Estupefacientes (en adelante Convención Única) fue firmada en 1961 y entró en vigor en 1964. A través de esta se unificaron la mayoría de tratados anteriores sobre drogas, desde la Convención Internacional del Opio (1912) hasta el Protocolo del Opio de Nueva York (1953). La Convención Única, el Convenio sobre Sustancias Psicotrópicas de 1971 y la Convención de las Naciones Unidas contra el Tráfico Ilícito de Estupefacientes y Sustancias Psicotrópicas de 1988, son los tres instrumentos principales del régimen internacional, del cual también hacen parte organismos como la Comisión de Estupefacientes, la Junta Internacional de Fiscalización de Estupefacientes (Jife), la Oficina de las Naciones Unidas contra la Droga y el Delito (Onudd) y la Organización Mundial de la Salud (oms).

La Convención Única amplió la restricción de la oferta del opio a otras plantas, incluidas aquellas de las que salen sustancias estupefacientes, como la adormidera (o amapola, de donde se extrae el opio), la coca y el cannabis, que durante siglos hicieron parte de tradiciones sociales, culturales y rituales de sociedades no occidentales (Sánchez, 2015). La Convención Única fue el primer instrumento en plantear explícitamente el objetivo de acabar con los "usos tradicionales y casi médicos" de esas plantas. En la Lista I de la Convención, la coca, el cannabis y el opio se metieron en la misma categoría que alcaloides extraídos como cocaína y morfina. El artículo 49 estableció un plazo de 25 años desde la entrada en vigencia del tratado (1964) para que se prohibiera definitivamente la masticación de la coca. Esto se reforzó con las convenciones de 1971 y 1988 , que sirvieron como base para una doctrina de política exterior estadounidense: combatir la 
oferta mediante el control de la producción en países de origen (Álvarez, 2011).

A finales de los 80 y durante los 90, en consonancia con las convenciones internacionales, se implementaron en Bolivia reformas neoliberales, programas de erradicación forzada y operaciones de interdicción. El Decreto 21060 de 1985 privatizó empresas estatales y generó la migración de más de veinte mil mineros desempleados a la provincia del Chapare, en el trópico de Cochabamba. Muchos encontraron en la coca una fuente de subsistencia y fortalecieron la organización sindical de los productores de la zona (Tellería, 2013 y Mattos, 2014). Esa migración crecería después por diferentes motivos, entre estos programas de colonización dirigidos por el gobierno durante la década de los 60. Gamboa (2009) y Prada (2012) encuentran que en los 70 el narcotráfico también fue un incentivo para la llegada de colonos no indígenas. Aunque en Bolivia se habían permitido desde siempre los usos tradicionales de la coca, en 1988 fue aprobada la Ley 1008, o Ley del Régimen de la Coca y Sustancias Controladas, que entendió como uso lícito la masticación, usos rituales y medicinales, pero hizo ilegal su cultivo exceptuando algunos sectores.

La Ley 1008 permitió la cooperación con gobiernos y organismos internacionales para combatir el narcotráfico (Ley 1008, 1988), con lo que abrió la puerta a la presencia militar de Estados Unidos particularmente en el Chapare. Así empezaron a generarse conflictos. Desde finales de los 80 hasta mediados de la primera década del siglo xxi hubo enfrentamientos entre productores de coca del Chapare y fuerzas de erradicación. Se fortaleció, como resisten- cia a la imposición de una agenda externa, el movimiento en defensa de la coca, al que se articularon sectores urbanos, rurales, sociales y mineros. Otros procesos organizativos surgían con motivo de una crisis socioeconómica estructural, que incluía un bajo crecimiento económico, nuevos impuestos y episodios violentos como la llamada "Guerra del Gas", en 2003. Ese año el presidente Gonzalo Sánchez de Lozada renunció. En 2005, Evo Morales era congresista, llevaba más de una década como líder cocalero, e impulsó protestas que llevaron al derrocamiento de otro presidente, Carlos Mesa.

Morales, candidato del Movimiento $\mathrm{Al}$ Socialismo (MAS), fue elegido presidente en 2005 y se posesionó en enero de 2006. En consonancia con las reivindicaciones de los movimientos sociales, como se verá en este artículo, Morales cambió el comportamiento del Estado frente al régimen internacional de control de drogas. Después de que se redactara la nueva Constitución del Estado Plurinacional de Bolivia en 2009, ese Estado presentó una propuesta de enmienda al artículo 49 (párrafo 1, inciso c y párrafo 2, inciso e) de la Convención Única, para eliminar la prohibición de la masticación de la coca. La propuesta no prosperó por objeción de 11 estados miembros. En 2011, Bolivia denunció el instrumento y el mismo año solicitó ser readmitido con una reserva al artículo 49. La readmisión fue aceptada en 2013. Con esto, Bolivia permitió el uso tradicional de la coca, siendo parte al mismo tiempo de una convención que la prohíbe.

Evo Morales no es el único responsable de los cambios adentro ni afuera de su país. Este artículo muestra que antes de que él llegara a 
la política, los movimientos sociales iniciaron un proceso hacia la revalorización de la coca. Además, gobiernos anteriores implementaron medidas que legalizaron cultivos de coca, como la polémica Ley 1008. En el ámbito internacional Bolivia no es el único en tomar reservas respecto a la coca. Perú y Argentina presentaron reservas para permitir la masticación de la coca desde que firmaron la Convención Única en 1961, aunque las retiraron cuando ratificaron el instrumento en 1963 y 1979 , respectivamente (Jelsma, 2011). Perú, como Bolivia, permite desde siempre el uso tradicional y desde 1949 ha liderado el comercio e industrialización de la coca mediante la Empresa Nacional de la Coca (Enaco) (Troyano y Restrepo, 2018). En Perú se considera la coca patrimonio cultural desde 2005. Argentina, por su parte, despenalizó la coca desde 1989 y dejó de considerarla estupefaciente. En 1988, al igual que Bolivia, Perú negoció el párrafo 2 del artículo 14 de la Convención contra el Tráfico Ilícito, el cual explica que para eliminar cultivos ilícitos se tendrán en cuenta los usos tradicionales lícitos donde al respecto exista evidencia histórica (onu, 1988). Tanto Perú como Bolivia expresaron además reservas a ese tratado de 1988, con el fin de proteger la masticación tradicional de la coca.

Colombia adhirió a la Convención Única en 1975. En 1994, al ratificar la Convención sobre Tráfico Ilícito de 1988, depositó una declaración diciendo, entre otras cosas, que el tratamiento a los cultivos de coca como ofensa delictiva "debe armonizarse con políticas de desarrollo alternativo, teniendo en cuenta los derechos de comunidades indígenas involucra- das y la protección del medio ambiente" (ONU, 1988 p. 5). Posteriormente, la Constitución de 1991 reconoció los derechos colectivos de pueblos originarios, con lo cual abrió la puerta al uso lícito de la coca en resguardos indígenas (Troyano y Restrepo, 2018).

Perú, Argentina y Colombia no han seguido el camino boliviano de la denuncia y readmisión con respecto a la masticación de la coca en la Convención Única. Bolivia, en cambio, al dejar este asunto plasmado como reserva en la convención, aporta un hecho jurídico internacional más claro, del cual aquí se analizará su condición de hegemónico y contrahegemónico. El problema de este artículo consiste en que el régimen internacional de control de drogas vigente prohíbe el cultivo de la coca en su estado natural y su uso tradicional. Sin embargo, impulsado por movimientos sociales, el Estado de Bolivia en 2011 denunció la Convención Única y luego fue readmitido con una reserva sobre la masticación de la coca. Ahora bien, la pregunta a responder es ¿por qué la defensa de la coca por parte de los movimientos sociales bolivianos, a través del Estado, puede entenderse como una práctica contrahegemónica en el régimen internacional desde la llegada de Evo Morales a la Presidencia?

Esto se resolverá mediante un análisis cualitativo, examinando la evidencia histórica, contextual y lógica sobre el régimen internacional, las reivindicaciones de los movimientos sociales bolivianos y del Estado frente al mismo. Se argumentará, con base en la revisión de los conceptos de hegemonía y contrahegemonía que aparecen principalmente en Ernesto Laclau y Boaventura de Sousa Santos, por qué 
esos movimientos pueden entenderse como contrahegemónicos en el régimen internacional.

\subsection{Hegemonía y contrahegemonía}

El concepto de hegemonía se puede rastrear desde Marx y el marxismo soviético, en autores como Lenin. Durante el siglo xx, con la publicación de la Cuestión meridional en 1930 y los Cuadernos desde la cárcel en 1975, el teórico marxista Antonio Gramsci construyó un concepto de hegemonía que pasa por la sociedad civil. Gramsci entendía la hegemonía como dirección política de alianzas necesaria para articular un bloque histórico. Pensaba que la hegemonía, antes que dominación o coerción, debía tener capacidad de dirección, búsqueda de consensos, articulación de intereses (Gramsci, 2002; 1975). Una de sus innovaciones respecto al marxismo-leninismo es la necesidad de que exista un grupo dirigente antes que dominante (Díaz-Salazar, 1991).

Ernesto Laclau es uno de los autores posmarxistas que hizo el desarrollo más importante del concepto de hegemonía de Gramsci. Para Laclau, hegemonía se entiende a partir del concepto de significante vacío. Un significante vacío es aquel que se desprende de los límites de su significado específico y pasa a representar los intereses de otros grupos particulares y diferenciados. El significante vacío es ambiguo, contradictorio e indeterminado, pues es posible gracias al "vaciamiento de un significante de aquello que lo liga a su significado diferencial y particular" (Laclau, 1996, p. 80).

El significante vacío es también hegemónico, pues la hegemonía es ese salto mediante el cual un grupo pasa a representar su lucha particular como universal en el espacio político. Ese salto se da mediante una articulación de intereses y una relación de equivalencia entre grupos diversos. Equivalencia, para Laclau y Mouffe, no implica la identificación de todos los intereses como iguales. No es tautológica y no sustituye unos intereses por otros, sino que se afirma "desde el punto de vista de su enfrentamiento común con un polo dominante" y en un "contexto estructural dado" (Laclau y Mouffe, 2004, p.109).

Santos aporta una perspectiva epistemológica importante para este artículo. Hegemonía y colonialismo se conjugan en su teoría del pensamiento abismal. El pensamiento occidental moderno es abismal y se inserta en el paradigma del conocimiento científico hegemónico (Santos, 2009). Está sustentado en el trazo de una línea que separa lo que constituye un conocimiento de lo que no. Al producir lo que está al otro lado de la línea como no conocimiento, se legitima a su vez lo que está a este lado de la línea, es decir, el conocimiento científico "universal". Pese a su alegada universalidad, en el pensamiento abismal es imposible la "co-presencia" de lo que está a ambos lados de la línea.

La "injusticia cognitiva” del pensamiento abismal es para Santos el presupuesto de injusticias sociales, subordinación y exclusión de prácticas y saberes no occidentales. La línea abismal tiene explicación en el colonialismo, pues es también la separación entre la metrópoli y la "zona colonial" (Santos, 2009, p. 162). Separación que se mantiene a pesar de las independencias y construcción de Estados-nación. De hecho, para Santos, el Estado nación 
moderno es monocultural y colonial, porque vive "a partir de una norma, que es una norma eurocéntrica que no celebra sino, al contrario, oculta la diversidad" (Santos, 2012, p. 21).

Santos (2012) ha estudiado los movimientos sociales bolivianos y, en particular, el referéndum constitucional de 2009, en el que Bolivia pasó del modelo hegemónico de Estado nación a un Estado plurinacional. Santos ubica dentro del concepto de contrahegemonía, o "globalización contrahegemónica" (Santos, 2014, p. 26), a aquellos procesos que, mediante instrumentos hegemónicos, reclaman su lugar de este lado de la línea abismal y visibilizan las injusticias cognitivas contra sectores que han sido producidos históricamente como inexistentes. Tapia (2011), desde una perspectiva cercana, exploró la transformación de la Constitución boliviana como un componente principal del "horizonte contrahegemónico" en América Latina.

El peruano Aníbal Quijano desarrolló el concepto de "colonialidad" del poder, como elemento constitutivo del patrón mundial de poder capitalista en la modernidad, que tiene fundamento "en la imposición de una clasificación racial/étnica de la población del mundo como piedra angular de dicho patrón de poder” (Quijano, 2007, p. 91). Para Quijano también hay colonialidad del saber, caracterizada por el eurocentrismo como única forma de entender el mundo. Sobre la continuidad del patrón colonial en América Latina, a través del colonialismo interno de élites criollas, también han profundizado autores bolivianos como Álvaro García Linera, Silvia Rivera Cusicanqui, Fausto Reinaga y René Zabaleta.
Otro autor clave para hablar del poder hegemónico de Occidente es el estadounidense Immanuel Wallerstein, quien exploró cómo el conocimiento de las ciencias sociales se produjo en lugares geográficos del Norte Global. En Wallerstein (1996), la economía mundo aparece regida por un Estado hegemónico que cambia en la historia, como lo fueron las Provincias Unidas (Holanda) a mediados del siglo XVII, Gran Bretaña a mediados del siglo xIX y Estados Unidos a mediados del xx. La lógica del capitalismo aparece ligada a la presencia del hegemón económico, militar y cultural llamado Estados Unidos.

\section{EL PODER HEGEMÓNICO DEL RÉGIMEN INTERNACIONAL DE CONTROL DE DROGAS}

Los principales centros de poder que impulsaron la construcción del régimen internacional de control de drogas son Europa, durante el período fundacional (1912-1931), y Estados Unidos, después de la segunda guerra mundial. Durante el primer período, se elaboró un marco regulatorio para el comercio de opiáceos, se buscó moderar un libre mercado, pero no prohibir ni criminalizar la producción. Para entonces, potencias coloniales como Francia, Gran Bretaña, Portugal y los Países Bajos se lucraban del comercio de opiáceos y abastecían mercados europeos y estadounidenses. Tras la segunda guerra mundial, Estados Unidos impulsó medidas más drásticas contra la producción, comercialización y consumo. Así se puso "una carga especialmente pesada sobre los países productores tradicionales" (Jelsma y Armenta, 2015, p. 3). Concretamente, sobre 
aquellos donde se producía coca, cannabis y adormidera, que estaban entre Asia, América Latina y África.

En la base de este régimen está la preocupación de las potencias del Norte por los usos no médicos ni científicos de substancias psicoactivas. La Convención Única trazó la línea divisoria entre lo científico y lo no científico. Esta categorización obligó a países a prohibir prácticas y saberes ancestrales, como la masticación de la coca, que quedaron por fuera de los conceptos de ciencia y medicina aceptados por el instrumento (Sánchez, 2015). El uso ancestral de la coca se permitió de manera excepcional y temporal, con la condición de que fuera abolido en un plazo determinado. La Convención sobre Tráfico Ilícito de 1988 incluyó el término "ilícito" y fortaleció la obligación de sancionar penalmente la producción, posesión y tráfico de sustancias controladas.

Con esta división entre lo científico y lo no científico, la Convención Única omite el valor epistemológico del uso tradicional de la coca. De entrada, anula el significado de la planta como práctica social, ritual, "medicinal", como un conocimiento clave en la forma de vivir y entender el mundo (Vidart, 1991; McAllister, 2000; Hesselroth, 2015). La Convención no tolera la co-presencia de prácticas y saberes. Santos (2009) dice que el conocimiento moderno le entrega el monopolio de lo verdadero y lo falso a la ciencia, y que la disputa entre verdadero y falso se da de este lado de la línea. Al otro lado, no puede hablarse de verdadero o falso, porque no hay conocimiento. Aunque la Convención Única permita temporalmente el uso tradicional de la coca y establezca márgenes de "flexibilidad" para que los Estados decidan o presenten reservas, en todo caso lo mantiene al otro lado de la línea, como aquello que es necesario abolir por no ajustarse al conocimiento científico ni a la medicina.

\subsection{La línea ideológica y moral de Occidente}

En la evolución del régimen internacional de control de drogas, la legitimación del conocimiento científico y médico no tiene una raíz fiel a su alegada neutralidad científica, sino explicaciones ideológicas y morales. En la construcción ideológica y moral del otro, como amenaza o enemigo, se fundamenta la necesidad de intervenirlo, de ponerle el traje único de Occidente.

Cuando se negoció la Convención Única, la oms fue encargada de clasificar las sustancias en las listas de control. Para esto, en 1949 una comisión visitó Bolivia y Perú y en 1950 presentó conclusiones al Consejo Económico y Social, en las que determinó que no solo indígenas sino mestizos tenían el "vicio" de la masticación de la coca, práctica que "inhibe el hambre", por lo que mantiene al consumidor en "un círculo vicioso de estado constante de desnutrición"; que es desfavorable a la "naturaleza intelectual y moral del individuo"; que disminuye el rendimiento económico en el trabajo y, por lo tanto, provoca un "nivel económico de vida muy bajo" (onU, 1950, pp. 99-100). Con base en esto, la Comisión recomendó la supresión gradual de la masticación de la coca. Aunque no existe evidencia científica para soportar esas conclusiones ni se ha comprobado que el uso tradicional de la coca sea tan perjudicial como para estar en 
la Lista I de la Convención Única, el Informe fue ratificado como reporte del Comité de Expertos de la oms desde 1952 en adelante.

Cuando se negociaban las convenciones, los países industrializados, en particular Estados Unidos, estaban preocupados por el consumo de drogas en sus territorios, más que por la evidencia científica sobre las materias primas. Tenían concepciones construidas con base en experiencias internas, mediadas por criterios de raza o nacionalidad. Se empezó a temer al opio cuando se asoció con los migrantes chinos, a la marihuana cuando se relacionó con los mexicanos, a la cocaína cuando se vinculó a la población negra, en tiempos de violencia racial en Estados Unidos (Musto, 1999). Pese a la demanda interna en esos países desarrollados, era en los productores donde se debía combatir la problemática. Como señala Jelsma, Estados Unidos tenía el mercado de drogas ilícitas de mayor crecimiento, pero "la respuesta política consistió en declarar la guerra a los suministradores extranjeros en lugar de analizar y abordar los motivos de la pujante demanda nacional" (2011, p. 6).

El término guerra contra las drogas lo utilizó por primera vez el presidente Richard Nixon en 1971, quien equiparó el abuso de drogas al enemigo público número uno. Con la caída del comunismo y los paradigmas de la guerra fría se replanteó en Estados Unidos la doctrina de seguridad y se identificó un nuevo enemigo: el narcotráfico (Salazar, 2009). Kai Ambos señala que esta guerra no fue contra la coca y la cocaína, sino una persecución de intereses hegemónicos estadounidenses, y que los límites ideológicos se encuentran citando al zar de las drogas de Clinton, Lee Brown, quien enfatizó ante la ONU que las drogas no son solo un peligro para la seguridad nacional sino para la democracia (Ambos, 1998).

Además de este sesgo ideológico, el régimen internacional tiene un matiz moral. El preámbulo de la Convención Única expresa la preocupación por la "salud física y moral de la humanidad" y se refiere a la toxicomanía como un "mal" (ONU, 1961)1. Escohotado (1999) e Inglis (1994) encontraron, entre los fundamentos de esta categorización, el rechazo de la tradición judeocristiana a los psicoactivos. El acceso a otros estados de conciencia producidos por medios diferentes a los aceptados es vinculado con la decadencia y la aberración. Pueden encontrarse referencias a lo demoniaco de la coca desde la llegada de los españoles en el siglo XV, quienes impusieron los primeros controles a esta planta en la región andina (Vidart, 1991). García Linera (2010, p. 462) dice que en 1550 fue planteada por primera vez la erradicación por parte de sacerdotes, "debido al rol que jugaba en la persistencia de los rituales precolombinos". Mientras era demonizada, la coca también fue monopolizada por comerciantes españoles que la proveían a campesinos e indígenas, para que aguantaran jornadas de trabajo forzoso en las minas, en el marco de la lógica extractivista de los poderes coloniales (Mattos, 2014; Galeano, 2015).

1 La versión en inglés de la Convención Única se refiere con el adjetivo "evil” a la adicción a las drogas narcóticas. 


\subsection{Colonialismo y asimetrías}

El régimen internacional de control de drogas reproduce ese esquema en que las potencias coloniales imponen su conocimiento, ideología y moral sobre naciones subordinadas. Esta asimetría se hace visible en lo favorable que resulta el régimen para las potencias hegemónicas. McAllister (2000) explica que al configurar las listas de control de la Convención Única, los países manufactureros discriminaron los intereses de productores y se privilegiaron con medidas más laxas. "Las materias primas [...] sufrieron las más severas restricciones bajo las listas I y IV. Algunos narcóticos manufacturados (principalmente con base en la codeína) recibieron de alguna manera un tratamiento más tolerante en las listas I y II". Jelsma (2011) señala que por presiones de la industria farmacéutica europea y norteamericana se concretó -en la Convención de 1971- un régimen menos rígido que dejó relativamente intactos los intereses de las farmacéuticas. Estas disparidades aplican también para el alcohol y el tabaco, sustancias que representan ganancias para Occidente, no reguladas por el régimen internacional y consideradas nocivas por la OMS.

En Bolivia, esta asimetría se tradujo en una drástica imposición de la política de drogas norteamericana, implementada por las élites bolivianas, es decir, por el colonialismo interno. Fue durante la dictadura militar de un criollo, Hugo Banzer, que el Estado ratificó la Convención Única en 1976. Desde ese año, Bolivia iría adquiriendo compromisos para luchar contra cultivos declarados ilícitos. Entre estos la Ley 1008 y la firma de tratados de cooperación con Estados Unidos entre 1982 y 2004, que permitieron implementar programas de erradicación forzosa, aseguraron apoyo militar estadounidense y operaciones conjuntas como la llamada "Alto Horno", realizada en 1986 con tropas del Comando Sur. También llevaron la Drug Enforcement Administration (DEA) a Bolivia y la Unidad Móvil de Patrullaje Rural (Umopar) contra el narcotráfico.

En 1992, cuando el presidente Paz Zamora propuso una enmienda a la Convención Única para abolir la prohibición de la coca, Estados Unidos lo evitó al condicionar la posibilidad de no seguir prestando asistencia financiera y militar a Bolivia. Presiones similares se vieron en 1995, durante el gobierno de Gonzalo Sánchez de Lozada (1993-1997), cuando Bolivia estuvo a punto de la descertificación por no cumplir las metas planteadas por Estados Unidos en la lucha contra el narcotráfico. A Sánchez de Lozada lo perdonó Estados Unidos, pero le puso más condiciones, como hacer un tratado de extradición, un plan de erradicación y acabar con 1.750 hectáreas de coca en el Chapare.

\section{LOS MOVIMIENTOS EN DEFENSA DE LA COCA}

Frente a la política de drogas impuesta desde Estados Unidos, en Bolivia la defensa de la coca se convirtió en elemento central de la lucha de diversos movimientos sociales. Para entender esto, primero hay que aclarar que esta defensa no se limita a "lo indígena", sino que se articula con intereses y organizaciones de campesinos, trabajadores, mujeres y otros gremios. Como dice García Linera, hay una conformación 
"híbrida y porosa de las clases e identidades sociales en Bolivia" (García, 2010, p. 15). Lo indígena y lo campesino se han mezclado en procesos comunes no solo alrededor de la coca, sino en la guerra del agua (2000), la guerra del gas (2003) y la defensa de la tierra. Desde el discurso oficial del Movimiento Nacionalista Revolucionario (MNR), que llegó al gobierno tras la revolución de 1952, los indígenas fueron entendidos dentro del campesinado (García, 2010). Esto se plasmaría luego en el artículo 2 de la Constitución de 2009, que garantiza la autodeterminación y autonomía a los "pueblos indígenas originarios campesinos".

Tras la revolución, indígenas y campesinos se organizaron en estructuras que tienen en la base sindicatos campesinos, luego subcentrales, centrales, federaciones y coordinadoras de federaciones. La Central Obrera Boliviana (СОв) fue el principal movimiento que desde 1952 influyó en esta estructura organizativa. El movimiento cocalero surgió en lugares que concentran la mayor producción de coca, donde se implementaron programas de erradicación. Estos son, por un lado, la provincia de los Yungas, que abarca principalmente el departamento de La Paz, en tierras altas. Allí habitan dos de los pueblos más importantes de la cultura andina: el quechua y aymara. La coca es central en su identidad cultural.

El indianismo katarista, que García (2010, p. 346) define como "una corriente política-cultural de reconstrucción-reinvención de la identidad nacional-indígena”, sería una de las principales fuerzas en utilizar la coca como "referente de una identidad colectiva, étnica y cultural”. Healey (1991, p. 92) apunta que este movimiento constituyó el sindicato más activo en el altiplano. En los 70 y 80, con su influencia, se creó la Confederación Nacional de Trabajadores Campesinos (СNTB) y la Confederación Sindical Única de Trabajadores Campesinos de Bolivia (СsuTCB), principal organización nacional que representa a quechuas, aymaras y tupí guaraníes, así como campesinos. Iniciativas de este movimiento como la formación de un Estado plurinacional y la revalorización de la coca, luego se plasmarían en la Constitución y serían reivindicadas por el Estado internacionalmente.

En los 80, los Yungas marcharon contra la erradicación. A finales de esa década fue aprobada la Ley 1008, durante el cuarto gobierno de Víctor Paz Estenssoro (1985-1989). Con esto, la zona fue designada para cultivo legal de coca para uso tradicional. Sin embargo, en los 90 se aplicó la erradicación a cultivos superiores a las 12.000 hectáreas, y contra esto se movilizaron más organizaciones locales, provinciales y regionales, reivindicando la organización ancestral indígena y la reconstitución del "ayllu como unidad organizativa" (Guery, 2012, p. 186).

La defensa de la coca en tierras altas tiene el reclamo indígena por la autonomía frente a poderes coloniales. Pero los Yungas no fue el principal escenario de la guerra contra las drogas. Esto sucedería en tierras bajas, en el trópico de Cochabamba y, sobre todo, en la provincia del Chapare, donde sindicatos cocaleros, compuestos en gran medida por colonos no indígenas, fueron los más activistas (Healey, 1991). La acción de estos sindicatos se dio como resistencia contra la erradicación forzada, principalmente durante el período neoliberal. Esto es, contra el plan "Opción Cero" (1993- 
1997), implementado en el gobierno de Gonzalo Sánchez de Lozada. También contra el Plan Dignidad (1997-2002) del gobierno de Hugo Banzer, que buscó eliminar la coca del trópico e introducir la Fuerza de Tarea Conjunta (FTC) compuesta por ejército, fuerza aérea, armada y Umopar. Y contra el Plan Bolivia (2002-2004), implementado en un período de alta conflictividad que terminó con la elección de Evo Morales como presidente.

El proceso de unificación de las federaciones del trópico de Cochabamba es importante. Como recoge Salazar (2009), entre 1986 y 1996 este tuvo como elemento común la defensa de la coca frente a la erradicación. En ese proceso, Evo Morales surgió como un líder cocalero capaz de hacer alianzas y generar acciones políticas. En 1988 llegó al cargo de ejecutivo de la Federación de Campesinos del Trópico de Cochabamba y fue elegido como presidente de la coordinadora de las cinco federaciones en 1994. En 1996 se creó la coordinadora de las Seis Federaciones del Trópico de Cochabamba y este, considera Salazar, es el momento "de mayor consolidación del movimiento sindical cocalero" (2009, p. 206).

Los resultados insuficientes de los programas de desarrollo alternativo y sustitución de cultivos que venían atados a programas de erradicación, así como las violaciones a los derechos humanos relacionadas con la militarización, fueron desde sus inicios fuente de conflictividad con cultivadores de coca. Salazar (2009) concluye que esos programas no acabaron la economía ilegal de la coca y no llegaron a más del 50\% de los cultivadores. Como respuesta, se organizaron movilizaciones para ejercer presión y exigir cambios (Hea- ley, 1991). No había movilizaciones aisladas, sino consensuadas desde la base hasta las altas instancias. Esto, según Quijano, permitió resistir ante la erradicación, y en esa resistencia los cocaleros ganaron "apoyo de otras fuerzas sociales, a las cuales han apoyado en sus propias luchas" (2005, p. 16).

Se desencadenaron enfrentamientos con Umopar y la DEA en el Chapare. Se militarizó el Trópico de Cochabamba. El gobierno fue obligado a negociar en ocasiones, pero también usó las armas para defender la erradicación. Durante los 90 las federaciones del trópico se "convirtieron en el movimiento social más activo de esa década, y el que más muertes tendrá entre sus miembros por efecto de la represión militar" (García, 2010, p. 400). Entre 1980 y 2004 la violencia en el trópico dejó al menos 95 civiles muertos, 23 integrantes de policía y militares, y 5.349 casos de violaciones a derechos humanos (Heselroth, 2015).

Salazar encuentra que el discurso cocalero del Chapare fue distinto al de tierras altas, porque la coca como elemento ancestral sería "una referencia secundaria" y, en primer lugar, estuvo la denuncia de la presencia norteamericana, "que cumple el rol de legitimador moral de la resistencia y la lucha social" (2009, p. 444). Contra ese enemigo común, el discurso en defensa de la coca tuvo alcance nacional. Los sindicatos y federaciones estaban afiliados o aliados con organizaciones nacionales como la csutcb, la Federación de Mineros de Bolivia, la Federación Nacional de Mujeres Campesinas de Bolivia Bartolina Sisa, entre otras, que se sumaron a la lucha contra el modelo neoliberal, teniendo como referente la coca. 
Con la relevancia alcanzada a nivel nacional, el movimiento cocalero se transformó en 1995 en un movimiento político portador del discurso de los movimientos sociales, el Movimiento Al Socialismo (MAS). El triunfo del MAS en las presidenciales de 2005 con Evo Morales como candidato, también fue producto de la relación conflictiva con Estados Unidos y sus políticas de erradicación.

Se ha visto que la defensa de la coca no fue solo la defensa de la planta ni de su uso ancestral, sino la representación de reivindicaciones de distintos sectores frente al modelo neoliberal. Mattos concluye que la coca como significante vacío, en términos de Laclau, sirvió como un nuevo proyecto nacional y como "símbolo" de resistencia frente a un enemigo común, como "punto de posicionamiento de resistencia y rechazo hacia lo hegemónico" (Mattos, 2014, p. 36). En efecto, la coca puede verse como símbolo articulador de un discurso hegemónico, que al desligarse de su significado particular aglutinó otros intereses y conquistó el espacio político nacional. Al ser un elemento central en el discurso de Morales, la coca aparece como un rasgo constitutivo de su liderazgo a nivel nacional. Sin embargo, la coca no ha dado el mismo salto en la representación desde lo local a lo internacional, que es lo que atañe a este artículo. El caso boliviano no deja de ser excepcional en el régimen internacional, donde impera la visión hegemónica occidental sobre la coca.

En el siguiente capítulo diremos por qué, pese a no ser hegemónico en el régimen internacional -entendiendo hegemonía en el sentido de Laclau-, el comportamiento del Estado puede entenderse como contrahegemónico, al visibilizar saberes y prácticas históricamente producidas como no existentes y marcar una pugna por una visión pluralista dentro de un modelo único.

\section{LA DEFENSA DE LA COCA POR PARTE DEL ESTADO}

Con Evo Morales llega una voz de los productores de coca al ámbito interestatal, en donde se toman las decisiones en el régimen internacional de control de drogas. Con este paso, como explica García (2010), la defensa de la coca se convierte también en una defensa de la patria, en contra de poderes externos. Aquí analizaremos cómo la defensa por parte de Morales ha ido en consonancia con los movimientos sociales de los que surgió.

La posesión de Morales fue en las ruinas de Tiwanako, en una ceremonia ancestral en el que la coca fue elemento ritual y en la que invitó a reevaluar los antecedentes indígenas de Bolivia y Los Andes (Hesselroth, 2015). El Plan Nacional de Desarrollo de 2006 reflejaba esa intención de revisar el monoculturalismo del Estado y favorecer una "visión multidimensional del desarrollo", que incorporara la defensa de recursos naturales y reconociera los derechos de poblaciones originarias (Svampa, 2012, p. 13).

Desde 2006 fue creado el Viceministerio de la Coca, responsable de promover el uso lícito de la coca y reglamentar la erradicación de cultivos excedentarios bajo un plan de compensación llamado "Control Social”. El mismo año, Morales empezó a mover su reivindicación "coca sí, cocaína no", y ante la Comisión de Narcóticos de la onu representantes de Bo- 
livia hablaban de revalorizar la coca. En 2007, Morales se opuso a implementar una directriz de la Jife que llamaba a prohibir la masticación de la coca y la producción del té de coca. En 2008, expulsó al embajador estadounidense y suspendió las operaciones de la DEA en Bolivia, iniciando un proceso de nacionalización de la política de drogas.

El Viceministerio de la Descolonización fue creado en 2009, hace parte del Ministerio de Cultura y busca revalorizar el conocimiento, valores y tradiciones ancestrales. Dos elementos claves en esto, señala Hesselroth (2015), son la lucha contra el colonialismo interno y a favor del reconocimiento de la cultura indígena, y la lucha contra el orden económico neoliberal. Estas fueron, como vimos en el punto 2, reivindicaciones de los movimientos sociales.

Morales impulsó, en 2009, el referéndum del que surgió una nueva Constitución que estableció un "Estado Unitario Social de Derecho Plurinacional", en consonancia con el llamado que hicieron movimientos sociales décadas atrás. Para muchos de estos movimientos, el modelo de Estado-nación hegemónico significaba un despojo de sus identidades concretas, de sus diferencias y derechos como pueblos originarios. La coca, como elemento central de la identidad indígena originaria campesina, es también central en este proyecto plurinacional. La Constitución de 2009, en el artículo 384, protege la "coca originaria y ancestral como patrimonio cultural, recurso natural renovable de la biodiversidad [...] y como factor de cohesión social”. Aclara, además, que la coca en estado natural no es un estupefaciente, y que se regirá mediante ley su "revalorización, producción, comercialización e industrialización”.

\subsection{El proyecto plurinacional en el régimen internacional de control de drogas}

Con el impulso de la reforma constitucional de 2009, Bolivia hizo la propuesta de enmienda para que se eliminara el artículo 49 de la Convención Única, que estableció que la masticación de la coca debía eliminarse en un plazo de 25 años. Estados Unidos se opuso y logró que 18 países objetaran la iniciativa (Hesselroth, 2016). En esa propuesta de enmienda, sin embargo, Bolivia recibió el apoyo de toda América del Sur y España, mientras que los que objetaron fueron la mayoría de países árabes y de Europa Occidental, además de Japón y Estados Unidos (Sánchez, 2012). Ante el rechazo a la propuesta de enmienda, en 2011 Bolivia denunció la Convención Única. En 2013, como resultado de un lobby alrededor de la coca, Bolivia fue readmitida con una reserva sobre la producción y masticación.

Desde que no logró la enmienda, Bolivia no ha formado una coalición suficiente para cambiar las convenciones. Como explica Sánchez (2012, p. 28), en el caso de la Convención Única la reubicación de una substancia en las listas de control requiere el consenso de la mayoría de los 53 Estados parte de la Comisión de Estupefacientes. Entre estos, los países árabes, los antiguos miembros de la Unión Soviética y de Europa Oriental, así como Japón y Estados Unidos constituyen un bloque que rechaza el cambio. Al observar el comportamiento de Bolivia en el sentido normativo-político, diríamos 
que carece de capacidad para formar alianzas suficientes alrededor de la coca en el régimen internacional. El discurso del movimiento cocalero no tiene internacionalmente una fuerza hegemónica como la que alcanzó al interior del país. Pero esta respuesta no es absoluta, porque la readmisión de Bolivia en la Convención Única implicó un apoyo mayoritario tácito. Solo 18 países objetaron la readmisión y 168 la respaldaron de manera pasiva (Tellería, 2013).

Bolivia como Estado no ha querido retirarse, sino adaptarse al régimen internacional de acuerdo con sus particularidades. Esto tiene un significado político y epistemológico contrahegemónico. Con la readmisión a la Convención Única, Morales logró que en este régimen se reconozca, al menos tácitamente, la diferencia. En vez del discurso único y homogéneo, se transita hacia a un discurso único y plural, donde se afirma la coexistencia (o copresencia) de diferentes prácticas y saberes: tanto las que se adecúan al modelo hegemónico como las que no. Promover que el traje único sea a la vez plural va en consonancia con el proyecto de plurinacionalismo en Bolivia. Que un Estado pueda permitir legalmente una práctica particular, que al mismo tiempo está prohibida como regla general, abre nuevos diálogos sobre la transición del paradigma científico único y dominante hacia otro construido a partir del respeto por -o la "celebración de", en términos de Santos (2009)- las prácticas y saberes diferentes de ese conocimiento hegemónico. Como explica Tellería (2013, p. 106), lo importante en este caso es que se invita a pensar la normativa internacional "desde el lente de las particularidades".
Silvia Rivera y Esteban Ticona señalan que la descolonización puede entenderse como un giro del centro epistemológico, a través del cual se reconocen otras formas de conocimiento (Howard, 2010). Este giro se refuerza con el reiterado discurso de Morales en instancias nacionales e internacionales. El presidente constantemente habla en defensa de la coca, la ofrece en su estado natural o en productos derivados o la mastica. Aunque se le ha criticado por hacer de la descolonización un producto mediático sin implementar a cabalidad el plurinacionalismo de pueblos andinos (Hesselroth, 2015), puede considerarse que el discurso -así como su reproducción mediática- también es constructor de conocimiento y realidades sociales. El cambio del discurso sobre la coca es significativo, porque abre nuevas formas de entendimiento frente al discurso hegemónico.

Desde su posesión, Morales prometió cambiar la Ley 1008. El 24 de febrero de 2017, la Asamblea Legislativa aprobó una nueva Ley General de la Coca (Ley 906), que amplía la superficie legal de cultivos pasando de las 14.000 hectáreas de la Ley 1008, a 22.000. La nueva medida insta a avanzar en la revalorización, la industrialización y la comercialización de la coca hacia otros países (Ley 906, 2017). Desde 2013, cuando Bolivia fue readmitida en la Convención Única, Morales ha presionado para que se autorice la comercialización internacional de productos hechos a base de coca. Esto es contrario a la Convención, que solo permite la comercialización para usos médicos y científicos autorizados. En enero de 2017 Morales anunció, sin embargo, que logró un acuerdo con Ecuador para exportar 
a ese país mate de coca y otros "derivados con fines benéficos", y que se adelantan gestiones para exportar a Venezuela, Paraguay y posiblemente a Europa.

Entre las críticas que se hacen a Morales, autores como Canessa (2014) y Hahn (1996) señalan que la identidad étnica indígena ha sido central en la construcción de Bolivia como nación indígena, pero a la vez ha ido en contra de la ancestralidad y las necesidades propias de los pueblos indígenas. Canessa dice que el gobierno de Morales, en vez de celebrar la diversidad indígena, creó una visión homogénea de lo indígena alrededor de la coca, en contra de su propio proyecto plurinacional. Señala además que los cocaleros -no todos ellos propiamente indígenas- se han movilizado contra programas de erradicación para defender sus propios intereses económicos, pero apelando al discurso indígena sobre la coca. Hahn dice que la сsUтсв tenía la reivindicación de defender a una "clase" indígena explotada, reivindicar la identidad étnica y las relaciones de producción no capitalistas propias de los indígenas, pero las demandas que llevó al Estado no estaban orientadas hacia estos cambios, sino que empujaron a la población indígena a mantenerse dentro del modo capitalista de producción (Hahn, 1996).

La distancia que estos autores encuentran entre el significado específico de la coca en el mundo indígena y el significado mucho más amplio e indeterminado que tiene como representación de intereses diversos, confirma una parte de nuestro argumento. Que la coca sirva como representación de sectores sociales diferentes e incluso antagónicos entre sí, incluyendo a aquellos que desvían la coca a mercados ilegales ${ }^{2}$, es muestra de su carácter hegemónico en la política boliviana. No se trata aquí de idealizar la coca y los intereses a su alrededor, sino de identificarla como articulador de un discurso hegemónico en el espacio político nacional, sin caer en juicios de valor o peyorativos.

Hahn encuentra también que, en vez de empoderar a los indígenas, la CSUTCB sirvió al Estado como instrumento de asimilación de estas comunidades al orden neoliberal y sus modos de producción. Considero que para la problemática de la asimilación no son suficientes las categorías de modos de producción. Santos, como hemos mostrado, arroja horizontes interpretativos para responder a esto. Lo contrahegemónico no es una respuesta enteramente diferente al capitalismo, ni un nuevo orden hegemónico que reemplace al capitalismo y sus formas de producción. En cambio, es aquello que reclama su lugar a este lado de la línea abismal y lo hace mediante instrumentos e instituciones del sistema jurídico, político y económico propio de la modernidad occidental. Por ejemplo, el referendo constitucional con el que Bolivia pasó a ser un

\footnotetext{
2 Gamboa (2009) señala que con el crecimiento de hectáreas de coca legales también han crecido las excedentarias, de donde sale la coca para ser convertida en cocaína, y que el incentivo del narcotráfico permea a los movimientos que apelan al discurso indígena. Esta realidad no pasa inadvertida, aunque no desvirtúa el argumento según el cual la coca como elemento de representación puede articular intereses diversos, sean legales o ilegales.
} 
Estado plurinacional, es contrahegemónico porque utiliza instrumentos e instituciones hegemónicas como la Constitución y el Estado de derecho (Santos, 2010b). Lo mismo podría decirse de la coca, que está plasmada en la Constitución boliviana y que tiene su efecto jurídico internacional en la readmisión en la Convención Única, un tratado hecho a la medida del discurso hegemónico en el régimen internacional.

Además, al ser impulsada la industrialización y venta legal de la coca y sus productos derivados, esta entra en la lógica del mercado capitalista. Esto se puede entender no como asimilación, sino como la confirmación de que en el sistema económico hegemónico pueden surgir y coexistir movimientos contrahegemónicos que reclaman un lugar a este lado de la línea, aunque no lleguen a imponer sus modos de producción. En este sentido, la comercialización de la coca también puede verse como contrahegemónica.

\section{CONCLUSIÓN}

El carácter hegemónico y colonialista del régimen internacional de control de drogas se manifiesta en que anula el valor epistemológico de prácticas como la masticación de la coca, puestas al otro lado de la línea, en el campo de lo que no es conocimiento. El régimen es hegemónico, porque anula la otredad y sobre la misma impone una visión única occidental. $\mathrm{Y}$ es colonialista, porque tiene en su base la estructura que divide la metrópoli de la zona colonial, estructura que permanece vigente y privilegia a los países del Norte Global.
El carácter de los movimientos sociales en Bolivia puede observarse desde la idea de hegemonía de Laclau, pues alcanzaron a nivel nacional la representación de grupos diversos alrededor de un elemento común, la defensa de la coca. No puede decirse lo mismo del comportamiento de los movimientos sociales, a través del Estado, frente al régimen internacional. La relación de equivalencia necesaria para formar un bloque hegemónico no se ha dado del mismo modo internacionalmente. La despenalización universal de la coca sigue siendo lejana. Bolivia tiene pocas posibilidades de articular una mayoría de intereses para reformar las convenciones y abolir la prohibición. No obstante, como se vio en el punto 3, dicho bloque existe de manera pasiva, con lo cual establece una pugna por un proyecto a largo plazo, de descolonización del saber y del poder en el régimen internacional.

El discurso de Morales sobre la coca no es hegemónico en el régimen internacional en el sentido de Laclau, pero sí contrahegemónico desde la perspectiva que aporta Santos. Bolivia no lidera una coalición capaz de cambiar el orden establecido, pero logró que el uso tradicional de la coca en sociedades no occidentales sea reconocido como un conocimiento válido, visible de este lado de la línea. En este sentido los movimientos sociales tienen, a través del Estado, una postura contrahegemónica, porque reafirman saberes y prácticas cuyo valor ha sido producido como no existente. Además, con la readmisión de Bolivia en la Convención Única se puso una excepción en el paradigma científico hegemónico del conocimiento que sustenta el régimen internacional de control de drogas, 
mediante el reconocimiento tácito de las diferencias dentro del mismo y del valor que tiene la coca para los pueblos andinos. Hablamos, entonces, de una contrahegemonía que permite la diferencia, el pluralismo, la co-presencia de distintas formas de conocimiento. En esta contrahegemonía, el conocimiento científico no es anulado, sino comprendido como uno más entre otros conocimientos con igual valor epistemológico.

\section{REFERENCIAS}

Álvarez, C. (2011). Política antidrogas de Estados Unidos. En Vargas, A. (Ed.), Fuerzas Armadas en la politica antidrogas: Bolivia, Colombia y México. Colombia: Universidad Nacional.

Ambos. K. (1998). Control de drogas. Política y legislación en América Latina, EE.UU. y Europa. Eficacia y alternativas. Colombia: Ediciones Jurídicas Gustavo Ibáñez.

Canessa, A. (2014). Conflict, claim and contradiction in the new "indigenous" state of Bolivia. En Critique of Anthropology, vol. 32 (2) pp. 153-173.

Constitución Política del Estado Plurinacional de Bolivia [Const.]. 2009.

Díaz-Salazar, R. (1991). El proyecto de Gramsci. Barcelona: Editorial Anthoropos.

Escohotado, A. (1994). Las drogas. De los origenes a la prohibición. Madrid: Alianza Editorial.

García, A. (2010). Sociología de los movimientos sociales en Bolivia. Estructuras de movilización, repertorios culturales y acción política. Bolivia: Plural Editores.

Gamboa, F. (2009). Cocaleros en el gobierno: un enfoque crítico sobre el complejo coca-cocaína en la Bolivia del siglo xxi. En Reflexión Política, vol. 11, No. 21.
Gramsci, A. (1975). Cuadernos de la cárcel. México: Juablos Editor.

Gramsci, A. (2002). La cuestión meridional. Buenos Aires: Quadrata Editor.

Guery, R. (2012). Historia, colonia y derecho de los pueblos indígenas. En Santos, B. y Exeni, J. (ed.), Justicia indigena, plurinacionalidad e interculturalidad en Bolivia. Ecuador: Ediciones Abya-Yala.

Hahn, D. (1996). The Use and Abuse of Ethnicity: The Case of the Bolivian сsuтсв. En Latin American Perspectives, vol. 23 (2), pp. 91-106.

Healey, K. (1991). Political Ascent of Bolivia's Peasant Coca Leaf Producers. En Journal of Interamerican Studies and World Affairs, vol. 33 (1), pp. 87-121.

Hesselroth, A. (2015). The Decolonization of Bolivia's Antinarcotic Policy. En Revista de Estudios Bolivianos, vol. 21, pp. 60-99.

Howard, R. (2010). Language, Signs, and the Performance of Power. The Discursive Struggle over Decolonization in the Bolivia of Evo Morales. En Latin American Perspectives, vol. 37, No. 3, pp. 176-194. Sage.

Inglis, B. (1994). El juego prohibido. Historia social de las drogas. Gerona, España: Tikal Eds.

Jelsma, M. (06/2011). The Development of International Drug Control: Lessons Learned and Strategic Challenges for the Future. En First Meeting of the Comission Geneva, 24-25. Disponible en https:// www.tni.org/files/The\%20Development $\% 20$ of\%20International\%20Drug\%20Control_M. Jelsma2011.pdf

Jelsma, M. (2011). El retiro de la prohibición de la masticación de la coca. Propuesta de Bolivia para modificar la Convención Única. En Informe del Transnational Institute. Serie reforma legislativa en materia de drogas, No.11. Transnational Institute. Disponible en https://www.tni.org/files/download/ dlr11s.pdf 
Jelsma, M. y Armenta, A. (2015). Las convenciones de drogas de la ONU. Guía básica. Trasnational Institute. Disponible en https://www. tni.org/files/publication-downloads/primer unconventions_24102015-es.pdf

Laclau, E. y Mouffe, C. (2004). Hegemonía y estrategia socialista. Buenos Aires: Fondo de Cultura Económica.

Laclau, E. (1996). Emancipación y diferencia. Buenos Aires: Ariel.

Laclau, E. (2005). La razón populista. México: Fondo de Cultura Económica.

Ley 906. (2017). Ley General de la Coca. Estado Plurinacional de Bolivia: 2017. Disponible en https://www.ruralytierras.gob.bo/leyes/LEY\%20 GRAL $\% 20$ COCA $\% 20$ ovp.pdf

Ley 1008. (1988). Ley del régimen de la coca y sustancias controladas. Honorable Congreso Nacional de Bolivia. Disponible en: http://www.aipe.org. bo/public/lst_politicas_publicas_nac/LST_POLITICAS_PUBLICAS_NAC_ley_1008_es.pdf

Mattos, D. (2014). Coca y representación. La hoja de coca en la constitución de la nación boliviana en la época neoliberal. Latin American Research Review, vol. 49, No. 1. Estados Unidos: Latin American Studies Association.

McAllister, W. B. (2000). Drug Diplomacy in the Twentieth Century, Nueva York: Routledge.

Musto, D. (1999). The American Desease. Origins of Narcotic Contro. Nueva York: Oxford University Press.

Naciones Unidas. (1950). Informe de la Comisión de Estudio de las Hojas de Coca. Duodécimo período de sesiones, Suplemento especial, No. 1. Nueva York: Centro de Documentación e Información.

Naciones Unidas. (1961). Convención Única de 1961 sobre Estupefacientes. Enmendada por el Protocolo de 1972 de Modificación de la Convención Única de
1961 sobre Estupefacientes. Disponible en https:// www.unodc.org/pdf/convention_1961_es.pdf

ONU. (1988a). Convention Against Ilicit Traffic in Narcotic Drugs and Psychotropic Substances. Disponible en https://treaties.un.org/doc/Treaties/1990/11/19901111\%2008-29\%20AM/ Ch_vi_19p.pdf

ONU. (1988b). United Nations Convention Against Ilicit Traffic in Narcotic Drugs and Psychotropic Substances (depositary notification). Viena. Disponible en https://treaties.un.org/doc/publication/ mtdsg/volume\%20i/chapter\%20vi/vi-19.en.pdf

Quijano, A. (2000). Colonialidad del poder, eurocentrismo y América Latina. En Lander, E. (ed.), La colonialidad del saber: eurocentrismo y ciencias sociales. Argentina: Clacso.

Quijano, A. (2005). El "movimiento indígena", la democracia y las cuestiones pendientes de América Latina. En Polis. Revista Latinoamericana. Disponible en https://polis.revues.org/7500

Quijano, A. (2007). Colonialidad del poder y clasificación social. En Castro-Gómez, S. y Grosfoguel, R. (ed.), El giro decolonial: reflexiones para una diversidad epistémica más allá del capitalismo global. Bogotá: Siglo del Hombre Editores.

Rivera, S. (2011). Coca. An Indigenous Commodity and Its Paradoxes. En Harvard Review of Latin America, vol. 11, No. 1, pp. 21-25. Boston: David Rockefeller Center for Latin American Studies.

Salazar, F. (2009). Movimientos sociales en torno a la producción de coca en Bolivia. Políticas de asentamiento, producción-erradicación de coca y desarrollo alternativo en el Trópico de Cochabamba Bolivia, 1920-2006. Bolivia: Instituto de Estudios Sociales y Económicos, Facultad de Ciencias Económicas Universidad Mayor de San Simón. 
Sánchez, C. (2012). El régimen internacional frente al 'problema' mundial de las drogas. Evolución, politicas alternativas y resistencia al cambio. San Diego: Trans-Border Institute.

Sánchez, C. (2014). El régimen internacional de control de drogas: formación, evolución e interacción con las politicas nacionales. El caso de la politica de drogas en España. Tesis doctoral. Barcelona: Universidad Pompeu Fabra.

Sánchez, M. (2015). Sistema Internacional de Fiscalización de las Drogas: La necesidad de un enfoque comprensivo para la efectiva protección de los derechos humanos. Tesis doctoral. España: Universidad Carlos III de Madrid.

Santos, B. (2009). Una epistemología del sur. México: Clacso.

Santos, B. (2010a). Descolonizar el saber, reinventar el poder. Uruguay: Ediciones Trilce.

Santos, B. (2010b). Refundación del Estado en América Latina. Perspectivas desde una epistemología del sur. Bogotá: Siglo del Hombre Editores; Universidad de los Andes; Siglo Veintiuno Editores.

Santos, B. (2012). Cuando los excluidos tienen derecho: justicia indígena, plurinacionalidad e interculturalidad. En Santos, B. y Exeni, J. (ed.), Justicia indígena, plurinacionalidad e interculturalidad en Bolivia. Ecuador: Ediciones Abya-Yala.

Santos, B. (2014). Si Dios fuese un activista de los derechos humanos. Madrid: Editorial Trotta.
Svampa, M. (2012). Movimientos sociales, gobiernos y nuevos escenarios de conflicto en América Latina. En Moreira, C. y Avaro, D. (ed.), América Latina Hoy. Sociedad y politica. Buenos Aires: Teseo.

Tapia, L. (2011). La configuración de un horizonte contra hegemónico en la región andina. En Revista Internacional de Filosofia Iberoamericana y Teoria Social, Utopía y Praxis Latinoamericana, No. 53, pp. 119-125. Venezuela: Cesa - FCES - Universidad del Zulia.

Tellería, L. (2013). Bolivia y la despenalización de la hoja de coca como estrategia de cambio. En URVIO, Revista Latinoamericana de Seguridad Ciudadana, No. 13, (junio), pp. 95-107.

Troyano, D. y Restrepo, D. (2018). La industrialización de la hoja de coca. Un camino de innovación, desarrollo y paz en Colombia. Nueva York: Open Society Foundations. Disponible en https://www. opensocietyfoundations.org/uploads/c5b0b8cf0c94-4040-bb45-93535b685a9c/path-to-innovation-evelopment-and-peace-in-colombiaes-20180521.pdf

Unodc. (2008). A Century of Interantional Drug Control. Disponible en https://www.unodc.org/documents/data-and analysis/Studies/100_Years_of_ Drug_Control.pdf

Vidart, D. (1991). Coca, cocales y coqueros en América Andina. Colombia: Editorial Nueva América. 